\title{
A saúde em região de fronteira: o que dizem os documentos do Mercosul e Unasul
}

\section{Health in the border area: what documents of Mercosur and Unasur reveal}

\section{Solange Aikes ${ }^{\mathrm{a}}$}

(D) https://orcid.org/0000-0002-7467-4804

E-mail: solange.aikesळgmail.com

\section{Maria Lucia Frizon Rizzotto ${ }^{b}$}

(D) https://orcid.org/0000-0003-3152-1362

E-mail: frizonळterra.com.br

aUniversidade Federal da Integração Latino-Americana. Foz do Iguaçu, PR, Brasil.

bUniversidade Estadual do Oeste do Paraná. Centro de Ciências Biológicas e da Saúde. Cascavel, PR, Brasil.

\section{Resumo}

Este artigo objetivou analisar o tratamento dado ao tema da saúde em região de fronteira no âmbito do Mercado Comum do Sul (Mercosul) e da União das Nações Sul-Americanas (Unasul). Para isso, realizou-se uma pesquisa documental em arquivos disponíveis nos sítios eletrônicos dessas instituições. Os dados foram tratados com base na técnica de análise de conteúdo. No Mercosul, o tema é abordado em várias reuniões do Subgrupo de Trabalho da Saúde, com a proposta, inclusive, de criação de um consórcio MercosulSaúde, que não se efetivou. 0 que avançou foram propostas relativas à harmonização de normas gerais de vigilância sanitária e epidemiológica. A recente criação do Subgrupo de Trabalho Integração Fronteiriça 18 gera novas perspectivas sobre os processos de transfronteirização. Na Unasul, observa-se uma visão mais solidária sobre o tema da saúde em região de fronteira, tendo como ponto de partida a garantia do direito à saúde aos residentes nesses territórios. Pode-se concluir que ambas as instituições assumiram importante papel no desenvolvimento e no processo de integração da região. Em contraponto, a integração social aparece de forma incipiente. Cabe aos cidadãos sulamericanos, em especial aos fronteiriços, o desafio de reconhecerem-se como parte integrante desses organismos e lutarem pelo reconhecimento do direito à saúde como direito humano fundamental. Palavras-chave: Áreas de Fronteira; Saúde na Fronteira; Mercosul.

\section{Correspondência}




\section{Introdução}

This article analyzed the treatment given to the subject of health in the border area concerning Mercosur and Unasur. For such, a documentary research was performed in archives available in the electronic websites of these institutions with the keywords "health" and "border". The data were analyzed using content analysis. In Mercosur, the subject is addressed in several meetings of the Subgroup on Health Work with the proposal of creating a Mercosur-Health consortium, which did not take effect. What it has advanced are proposals for the harmonization of general standards for health and epidemiological surveillance at borders. The recent creation of the Border Integration Working Subgroup 18 points to a greater concern with cross-translational processes. In Unasur, a more sympathetic view on the health issue in border area is observed, starting from the guarantee of the right to health to residents in these territories. Both institutions are shown to have played an important role in the development and integration process of the area. In contrast, social integration appears in an incipient manner. It is the responsibility of South American citizens, especially the border people, to recognize themselves as an integral part of these organizations and to fight for the recognition of the right to health as a fundamental human right. Keywords: Border Areas; Border Health; Mercosur.
A formação de blocos regionais de Estados próximos por interesses econômicos comuns é uma das consequências do processo de globalização. No cenário atual das relações internacionais, a integração regional é realidade inegável e possivelmente irreversível, dada a interdependência entre os países. Na América do Sul, nas últimas décadas, ocorreram movimentos e dinâmicas variadas de acordos com o objetivo de avançar na integração regional. São exemplos desse processo a Associação Latino-Americana de Integração (Aladi), a Alternativa Bolivariana para a América (Alba), a Comunidade Andina de Nações (CAN), a Comunidade Sul-Americana de Nações (Casa) e a União das Nações Sul-Americanas (Unasul), além do Mercado Comum do Sul (Mercosul) (Gomes, 2015).

A integração sul-americana encontra dificuldades internas que são causadas pelas desigualdades econômicas e as diferenças culturais, sociais e político-ideológicas, além de conflitos territoriais. Na integração, é necessário que as partes tenham diálogo e planejamento conjunto, criando um ciclo dinâmico em que as capacidades e recursos particulares de cada país possam ser maximizados. Entre os anos de 2004 e 2008, em toda a América do Sul, foram eleitos governos progressistas que contribuíram para um clima político de integração sul-americana e de modelos de desenvolvimento semelhantes (Krykhtine, 2014), mas isso corre o risco de ser revertido ou ao menos estancado nos próximos anos, com eleições de governos liberais, que não apostam na integração latino-americana como alternativa à lógica da globalização econômica e financeira.

Devido ao seu tamanho e localização geográfica, o Brasil ocupa uma posição vantajosa nos vínculos criados com os outros países latino-americanos. Participa de duas iniciativas que procuram promover a cooperação e o desenvolvimento regional, o Mercosul e a Unasul, sendo estas o recorte desta pesquisa.

O Mercosul foi formalizado em 26 de março de 1991, composto inicialmente por Argentina, Brasil, Paraguai e Uruguai. Em 2012, o bloco passou pela primeira ampliação desde sua criação, com 
o ingresso definitivo da Venezuela como Estado Parte, atualmente suspensa. No mesmo ano, foi assinado o protocolo de adesão da Bolívia que, uma vez ratificado, fará do país andino o sexto membro pleno do bloco. Ainda conta com Estados Associados: Chile, Colômbia, Equador, Peru, Guiana e Suriname. Caracteriza-se como modalidade de integração denominada união aduaneira, etapa intermediária para o alcance do mercado comum, caracterizada pela livre mobilidade de fatores produtivos (capital e trabalho), adoção de política comercial comum (tarifa externa comum) e coordenação de políticas macroeconômicas e setoriais. Com o desenvolvimento do bloco, diversas políticas públicas como educação, saúde, justiça, cultura e transportes, entre outras foram incorporadas as discussões (Mercosul, 2016a).

Já o acordo concretizando a criação da Unasul ocorreu em 11 de março de 2011, quando teve início a vigência do Tratado Constitutivo, embora sua negociação tenha começado em 2004. Trata-se de uma união intergovernamental entre os 12 países que compõem a América do Sul - Argentina, Bolívia, Brasil, Chile, Colômbia, Equador, Guiana, Paraguai, Peru, Suriname, Uruguai e Venezuela - que juntos ocupam um território de 17,8 milhões de km2 (Buss; Ferreira, 2011; Unasul, 2016).

Anteriormente, a América do Sul se relacionava com outros países de maneira isolada e desintegrada; com a Unasul, os países da região passaram a se articular em torno de áreas estruturantes, como energia e infraestrutura, e a coordenar posições políticas comuns em reuniões e assembleias de organismos internacionais. A instituição defende um modelo de desenvolvimento interno e tem por objetivo construir um espaço de integração cultural, econômico, social e político (Unasul, 2016).

Apesar das diferenças sociais e econômicas que caracterizam os países sul-americanos, a contiguidade geográfica e a proximidade cultural facilitam os fluxos migratórios. O Brasil tem uma faixa de fronteira terrestre de $15.719 \mathrm{~km}$, que corresponde aproximadamente a $27 \%$ do território nacional, com cerca de 11 milhões de habitantes. Nessa região de fronteira, estão sediados 588 municípios, distribuídos em 11 estados que fazem divisa com 10 países da América do Sul, onde são identificadas simetrias e assimetrias próprias desses espaços territoriais (Neves et al., 2016).

O fenômeno denominado de transfronteirização pode ser entendido como um conjunto de processos de aproveitamento de uma fronteira. No âmbito desses processos, os habitantes transcendem a fronteira, imposta pelos Estados como uma barreira/limite, e a incorporam em suas estratégias de vida. Por muito tempo os Estados Nacionais marginalizaram os espaços fronteiriços, mas os transfronteiriços asseguraram a continuidade das interações (Carneiro, 2016). A legitimação dos processos de transfronteirização existentes nesse território demanda regras especiais de funcionamento, respaldadas por acordos bi ou multilaterais, já que transcendem a escala local e envolvem sistemas políticos e sociais distintos que requerem intervenção do nível nacional de governo.

A busca de direitos sociais nos diferentes lados da fronteira é uma característica da transfronteirização. Em relação aos fluxos dirigidos ao Brasil, a maior parte deles se relaciona aos serviços públicos de saúde e, secundariamente, de educação. A universalidade e a integralidade legitimadas pelo Sistema Único de Saúde (SUS) são apontadas como características determinantes para que ocorra esse deslocamento. A utilização dos serviços de saúde brasileiros por cidadãos dos países vizinhos tem se tornado uma preocupação das autoridades envolvidas, argumentando que a ampliação da demanda pode contribuir para uma sobrecarga do SUS nessas localidades (Scherma; Oliveira, 2014).

Estudos que abordaram o tema da saúde nas fronteiras identificaram que há uma demanda, não dimensionada, de serviços de saúde por estrangeiros e os atendimentos realizados em geral não têm continuidade por serem quase sempre de caráter emergencial, o que dificulta inclusive a vigilância e o controle epidemiológico de doenças. Entre os gestores municipais, os estudos observaram dois posicionamentos: (1) os que entendem ser o atendimento ao estrangeiro um direito pautado na preservação da vida e, portanto, os atendem independentemente de qualquer critério restritivo; e (2) os que entendem o direito à saúde como restrito aos nacionais e intensificam os mecanismos de controle. As duas situações não se encaminham para 
soluções mais equitativas, éticas e politicamente negociadas (Agustini; Nogueira, 2010; Giovanella et al., 2007; Lemos; Ruckert, 2011).

A saúde, como um direito fundamental inscrito na Declaração Universal dos Direitos Humanos, deve ser garantida por medidas de caráter nacional e internacional (ONU, 1948). As regiões fronteiriças compõem um território próprio, cujos problemas nem sempre podem ser resolvidos a partir de uma perspectiva nacional, como é o caso do direito à saúde, assegurado entre outros pelo acesso a serviços de diferentes níveis de atenção. Nessa perspectiva, este trabalho objetiva analisar o tratamento dado ao tema da saúde em região de fronteira no âmbito do Mercosul e da Unasul.

\section{Materiais e métodos}

O delineamento dessa investigação ancora-se no referencial da pesquisa social, com abordagem qualitativa de natureza descritiva e documental. A pesquisa documental consiste em identificar, verificar e apreciar documentos com finalidade específica e, nesse caso, preconiza-se a utilização de uma fonte paralela e simultânea de informação para complementar os dados e permitir a contextualização das informações contidas nos documentos. A pesquisa documental se caracteriza pelo estudo de documentos que ainda não receberam um tratamento analítico em relação a determinado objeto de estudo, mesmo que ele já tenha sido analisado outras vezes sob o olhar de outro objeto de estudo (Cechinel et al., 2016).

Os documentos que constituíram o corpus de análise foram obtidos nos sítios eletrônicos oficiais do Mercosul e da Unasul, utilizando as ferramentas de buscas online disponibilizadas, por meio das palavras-chaves "saúde" e "fronteira", em português e espanhol. Não se fez distinção de documentos pela sua tipologia ou idioma, trata-se de atas, relatórios, declarações, projetos, acordos e resoluções, entre outros, em sua maioria redigidos em espanhol. Os dados foram coletados em novembro de 2016 e os documentos transferidos para pastas específicas, organizados em planilha Excel, contendo tipo de documento, ano de publicação, título e uma breve resenha do conteúdo de cada um. Após esse procedimento inicial, aqueles documentos identificados com o tema em estudo foram individualmente apreciados, utilizando-se para isso a técnica de análise de conteúdo que compreende pré-análise, exploração do material e inferência e interpretação (Bardin, 2011).

A busca dos documentos referente ao Mercosul foi realizada no site da instituição, ${ }^{1}$ com os seguintes procedimentos: gestor documental normativa - pesquisa - pesquisa básica - palavra a pesquisar: saúde e fronteira. Nessa busca geral, foram encontrados 231 documentos, oriundos de Reuniões de Ministros do Mercosul (RMS) e do Subgrupo de Trabalho da Saúde (SGT-11), além do documento de criação do Subgrupo de Trabalho Integração Fronteiriça (SGT-18). Dos 231 documentos, 71 abordavam o tema da saúde e continham a palavra fronteira em seu texto, sendo objeto de pré-análise. Após esse procedimento, 25 documentos foram selecionados para compor o corpus do estudo.

$\mathrm{Na}$ Unasul, a busca também foi feita no site da instituição, ${ }^{2}$ utilizando as palavras-chaves "salud" e "frontera". Obteve-se 39 abas no sítio eletrônico com diversos arquivos, que ao final totalizaram 156 documentos. Destes, 11 eram repetidos; um deles era o Regulamento Sanitário Internacional de 2005; e 126, apesar de abordarem temas relacionados à saúde pública, sistemas públicos e universais de saúde, educação em saúde, entre outros, não faziam menção ao tema saúde em região de fronteira, restando 18 documentos para análise. Assim, no total foram analisados 43 documentos de ambas as instituições objeto do estudo.

\section{Resultados e discussão}

Tanto o Mercosul como a Unasul já conquistaram uma posição de destaque internacional e são instituições que abordam o tema saúde, entendendo-a como importante aliado ao processo de desenvolvimento regional. A seguir, apresentam-se os resultados das análises dos 
documentos obtidos nos sítios eletrônicos dessas instituições, buscando identificar como elas tratam o tema da saúde em região de fronteira.

\section{A saúde em região de fronteira no âmbito do Mercosul}

As RMS e o SGT-11, criado em 1996, são as instâncias centrais para abordar o tema da saúde no Mercosul. O SGT-18 foi incluído pela pertinência ao objetivo da pesquisa. Cabe destacar que nos subgrupos as discussões são realizadas com base em pauta negociadora, documento que determina prioridades e estima prazos para seu cumprimento (Trindade, 2016). Desde sua criação, o SGT-11 teve três pautas negociadoras, sendo a primeira em 2001, a segunda em 2005 e a terceira em 2007. Na de 2001, está estabelecido como objetivo do subgrupo harmonizar as legislações dos Estados Partes referentes a bens, serviços, matérias-primas e produtos da área da saúde, os critérios para a vigilância epidemiológica e o controle sanitário com a finalidade de promover e proteger a saúde e a vida das pessoas e eliminar os obstáculos ao comércio regional, contribuindo dessa maneira ao processo de integração (Mercosul, 2001).

Nenhuma referência é feita ao tema da saúde em região de fronteira nos objetivos iniciais do SGT-11. A questão central a ser debatida estava relacionada a aspectos gerais de produção e consumo de mercadorias e serviços relacionados à saúde, como o controle sanitário e de vigilância epidemiológica, sempre visando favorecer o comércio entre os países.

$\mathrm{Na}$ segunda pauta negociadora, de 2005 , os objetivos do subgrupo foram ampliados, contemplando a intenção de realizar algum grau de integração do setor saúde, expresso nos objetivos de "promover e gerenciar propostas de cooperação que visem à integração regional no setor saúde; promover a atenção integral à saúde e a qualidade de vida das pessoas, mediante ações comuns no âmbito do Mercosul" (Mercosul, 2005a).

$\mathrm{Na}$ terceira pauta negociadora, de 2007 , manteve-se a ideia do trabalho de cooperação visando à integração no setor saúde e foi incluído o desenvolvimento e atuação dos recursos humanos em saúde, conforme expresso nos objetivos: promover e gerenciar propostas de cooperação que visem à redução das assimetrias existentes e a integração regional no setor saúde. Propor e coordenar diretrizes com vistas ao desenvolvimento dos profissionais da saúde, para o seu exercício profissional no âmbito do Mercosul. (Mercosul, 2007)

Além disso, nessa pauta negociadora, pela primeira vez aparece a proposta de "apoiar iniciativas de integração das ações de saúde nas fronteiras do Mercosul" (Mercosul, 2007), no entanto, sem discriminar como isso seria feito.

Apesar de em seus objetivos o SGT-11 abordar a necessidade de cooperação no setor saúde, não se observam discussões sobre a integração dos sistemas nem em relação ao acesso à saúde em regiões de fronteira, principalmente relativas ao cidadão transfronteiriço. Assim, verificou-se que as pautas negociadoras do SGT-11 resumidamente buscam a harmonização da legislação dos países no que se refere à produção e comercialização de produtos que tenham relação com saúde, vigilância epidemiológica e controle sanitário, e mais recentemente de formação e trânsito de recursos humanos no bloco.

Quanto à apreciação das atas do SGT-11, o tema da fronteira aparece relacionado mais a aspectos epidemiológicos e de vigilância sanitária, como o projeto apresentado pela delegação uruguaia: vigilância epidemiológica e sanitária em pontos de fronteira. A Ata SGT-11 $\mathrm{n}^{0}$ 02/200o faz referência a um acordo entre os coordenadores nacionais para "elaborar um marco orientador o qual deverá abordar as atividades bi ou trilaterais entre os Estados Partes para promover a saúde da população fronteiriça" (Mercosul, 200oa). Na reunião seguinte, foi apresentado, em parceria com a Organização PanAmericana de Saúde (Opas), o denominado Projeto de Cooperação Técnica em Saúde na região fronteiriça entre Argentina, Brasil e Paraguai (Mercosul, 200ob).

A partir da Ata $n^{0}$ 01/2002, a saúde nas fronteiras passou a ser um ponto específico, sendo que nessa reunião de 2002 foi relatada a criação do Grupo Ad-Hoc sobre Integração Fronteiriça (Gahif), sendo determinado, pelo Grupo Mercado Comum (GPM), que os subgrupos deveriam trabalhar em conjunto. No ano seguinte, foram entregues pela delegação 
brasileira dois documentos sobre o tema da saúde em região de fronteira, sendo eles: Subsídios para o Gahif e o Informe de la Trifrontera (Estudio de la Red de Servicios de Salud en la Región de Frontera: Brasil - Argentina - Paraguay: 2001-2002) (Mercosul, 2002, 2003a).

$\mathrm{Na}$ segunda reunião de 2003 , a delegação do Brasil apresentou a proposta de criação do Consórcio Mercosul-Saúde, com o objetivo de organizar a atenção à saúde nas fronteiras. As delegações concordam com a importância de avançar na consolidação de ferramentas de gestão capazes de responder às necessidades das populações fronteiriças e comprometeram-se a analisar a viabilidade da proposta (Mercosul, 2003b). No plano de trabalho 2004, anexo a essa ata, identificaram-se propostas de ações que tinham a fronteira como tema:

saúde nas fronteiras seguimento e articulação com o Gahif; projeto de cooperação técnica em epidemiológica e vigilância em saúde em áreas de fronteira; avançar o desenvolvimento da implementação do projeto em áreas de fronteiras terrestres do Mercosul. (Mercosul, 2003b)

Em 2005, foi apresentado o Projeto Integrado de Saúde nas Fronteiras do Mercosul (Sis-Mercosul) e em 2006 o projeto é mencionado, constando em ata que falta detalhamento para ser discutido com a Opas (Mercosul, 2005b).

Após 2006, houve um silêncio sobre o tema da saúde nas regiões de fronteira nas atas do SGT-11, sendo retomado em 2009, com a proposta da delegação do Uruguai no projeto intitulado "Fortalecimento na capacidade de resposta em saúde a nível nacional e em particular em zonas de fronteira: Uruguai - Brasil", que tinha por objetivo o fortalecimento das respostas sanitárias com ênfase na fronteira com o Brasil, diminuindo as assimetrias internas entre os dois países (Mercosul, 2009).

Nas Atas do SGT-11 n 02/2010, $\mathrm{n}^{0}$ 02/2011, $\mathrm{n}^{\mathrm{0}} \mathrm{01/2014}$ e, mais recentemente, $\mathrm{n}^{\mathrm{0}} \mathrm{02/2015}$, que aprovou o plano de trabalho 2015-2016, existe a menção de propostas de criação de mecanismos de vigilância e controle nas zonas fronteiriças para realizar diagnóstico e caracterização de trabalho em cidades de fronteira (Mercosul, 2010,
2011, 2014, 2015b). Seu status, nos relatórios desse plano de trabalho, revela que ainda são estudados mecanismos de implementação demonstrando a procura por um diagnóstico factual sobre aspectos epidemiológicos em municípios fronteiriços. Conforme identificamos, mesmo que em diferentes momentos a saúde em região de fronteira tenha sido objeto de discussão nas reuniões do SGT-11, não foi possível identificar, na documentação analisada, a efetivação das propostas apresentadas pelas diferentes delegações.

O SGT-18 foi instituído em 2015, por meio da Resolução no 59/2015. É coordenado pelos ministérios das relações exteriores dos Estados Partes e tem como objetivo:

promover o aprofundamento do processo de integração das comunidades fronteiriças dos Estados Partes criando um espaço de trabalho permanente com a finalidade de pôr em vigência programas conjuntos para alcançar um melhor desenvolvimento integrado desses territórios e comunidades. (Mercosul, 2016b)

O subgrupo iniciou os trabalhos com a revisão da pauta negociadora, documento que direciona os trabalhos e contém suas diretrizes e atribuições. Segundo a resolução, além de cumprir atividades administrativas, o SGT-18 deverá atuar em medidas que beneficiem as populações fronteiriças, com a elaboração de instrumentos normativos, a melhoria da comunicação e a articulação de projetos, incluindo aspectos de financiamento.

O SGT-18 publicizou na sua primeira reunião uma proposta para criação de mercorregiões, que serão constituídas levando em consideração as características regionais e deverão ser tratadas de maneira diferenciada conforme suas necessidades. Na pauta negociadora fica esclarecido que a atuação do SGT-18 é ampla, podendo atuar nas diversas áreas sociais, buscando responder às necessidades e anseios da população fronteiriça.

Por se tratar de um órgão que apenas recentemente conquistou a institucionalização merecida, não é possível uma análise mais aprofundada, mas se destaca como importante conquista para a população transfronteiriça, principalmente pela mudança de 
perspectiva que propõe para discutir os processos de transfronteirização no âmbito do Mercosul.

Em regiões de fronteira, a esfera social define-se nacional e internacional ao mesmo tempo. Há uma dinâmica social nas relações entre as populações fronteiriças, as quais, por vezes, driblam os mecanismos de controle das burocracias nacionais. No que se refere ao desenvolvimento e à integração da faixa de fronteira dos países do Mercosul, nota-se que a fronteira até os anos de 1990 aparece no contexto das trocas comerciais. A celebração do Acordo sobre Trânsito Vicinal entre os Estados Partes, promovido em 1999, foi um avanço sobre a questão da livre circulação de pessoas em cidades gêmeas, dando início a uma ampliação da visão a respeito do tratamento da integração fronteiriça. A visão integradora no Mercosul se expandiu em 2002, com a criação do Gahif, em 2004 com o Fórum Consultivo de Municípios, Estados Federados, Províncias e Departamentos do Mercosul e do Fundo para a Convergência Estrutural do Mercosul (Focem) (Desiderá Neto; Penha, 2016). O Parlasul, instituído em 2005, apesar de enfrentar entraves à sua institucionalização, também se destaca como órgão de representação dos povos no âmbito da integração sul-americana (Tajra; Martins, 2014).

Para a população transfronteiriça, a Rede Mercocidades, fundada em 1995, foi um marco, já que o órgão visa a que os atores subnacionais tenham voz e espaço de atuação para melhoria das políticas sul-americanas. Atualmente, conta com 323 cidades e seu papel inclui inserir as demandas dos cidadãos no processo de integração regional. Trabalham a partir de 15 unidades temáticas, uma delas denominada Integração Fronteiriça, que atua com o Foro Consultivo de Municípios, Estados Federados, Províncias e Departamentos do Mercosul (Campos, 2017).

Para que se avance na integração regional, faz-se necessário que se mantenham abertos os canais de participação social e que a garantia das necessidades fundamentais da população tenha tanta importância dentro da agenda do Mercosul quanto a desobstrução do comércio, a integração física e a redução das assimetrias (Bianchin; Schlogel; Maciel, 2016).
Entre outras iniciativas na dimensão social do Mercosul, é importante destacar o Plano Estratégico de Ação Social (Peas) e o Plano de Ação para Conformação do Estatuto da Cidadania (Desiderá Neto; Penha, 2016). 0 estudo de Desiderá Neto e Penha (2016), que avaliou o impacto nas fronteiras das 59 iniciativas listadas pela cartilha da cidadania do Mercosul, lançada em 2010, constatou que 49 têm impacto maior e positivo (83\%), quatro têm impacto maior e negativo (7\%) e seis não têm impacto maior (10\%). Esse diagnóstico preliminar corrobora o argumento de que esses territórios são laboratórios da integração, nos quais demandas são formadas e soluções são experimentadas, mesmo que em alguns casos não haja um fluxo formal entre uma coisa e outra.

Algumas ações identificadas nos documentos do SGT-11 propõem o diagnóstico dos processos de transfronteirização na saúde nos municípios de fronteira. Essa problemática de identificar e compreender o que ocorre nesses municípios é antiga: em 2005, o Mercosul propôs o programa Sis-Mercosul, que suscitou a expectativa de ser um processo de longo prazo com ações específicas para a questão da saúde dos transfronteiriços, sem, no entanto ter continuidade (Agustini; Nogueira, 2010).

Observa-se que o Mercosul proporciona um estreitamento de vínculos entre os Estados que podem auxiliar no avanço de políticas mais equitativas. Na criação da Nova Agenda para a Cooperação e o Desenvolvimento Fronteiriço (NACDF), em 2002, Brasil e Uruguai manifestaram uma compreensão sobre a singularidade da região de fronteira e se dispuseram a uma experiência inovadora em relação à integração. No entanto, a implementação das ações, até hoje, passa por entraves burocráticos e operacionais, revelando a dificuldade em transformar o idealizado em ações concretas. Esse projeto lançou as bases para a criação da figura jurídica do cidadão fronteiriço, que regula e binacionaliza os direitos (Scherma; Oliveira, 2014).

$\mathrm{Na}$ fronteira entre Brasil e Paraguai, por exemplo, com a securitização em função de questões como o contrabando, o descaminho e o tráfico de pessoas, jamais foi negociado um mecanismo que sequer se aproximasse desse modelo. A redução das 
assimetrias bilaterais e a superação de preconceitos são passos fundamentais para que um acordo dessa natureza seja assinado pelos países (Desiderá Neto; Penha, 2016).

Pelo exposto, verifica-se que no Mercosul principalmente o SGT-18 trabalha com um conceito mais ampliado de integração, perspectiva capaz de promover mudanças na direção de construir uma nova realidade. A integração supera a etapa do interesse dos participantes, visto que já foi internalizado na cultura política o pertencimento ao grupo regional (Candeas, 2010). Apesar de a integração ter evoluído como conceito e estar presente nas discussões desses órgãos no Mercosul há mais de 20 anos, na prática, nas cidades gêmeas os processos de transfronteirização na área da saúde ainda são tidos como ilegítimos e/ou inapropriados (Albuquerque, 2012).

\section{A saúde no âmbito da Unasul}

Foi possível verificar, após exploração do material, que os princípios contidos no estatuto geral da Unasul priorizam preceitos sociais, democráticos, solidários e de união entre os países participantes. Nos documentos de criação do Conselho de Saúde Sul-americano (CSS), em 2008, é possível identificar importantes diretrizes, dentre elas, saúde como direito fundamental da pessoa humana, saúde como indutor de integração entre os países da Unasul, solidariedade, respeito pela diversidade e interculturalidade. Além disso, há objetivos como a redução de assimetrias entre os sistemas de saúde dos Estados Membros e acesso universal aos serviços de saúde, com destaque para o objetivo de "privilegiar as ações da Unasul Saúde nas fronteiras” (Unasul, 2008, p. 2). Nesse sentido, entende-se que esse seja um reconhecimento do problema enfrentado pela população transfronteiriça.

Ainda no âmbito da vigilância em saúde, existem três resoluções de 2010, de números 4/2010, 5/2010 e $6 / 2010$ do CSS, as quais tratam sobre dengue, chagas e H1N1, mostrando a atuação da Unasul no combate a epidemias e doenças endêmicas que causam preocupação nos países membros. Nos documentos analisados, existe a preocupação de vigilância e controle de doenças nas regiões fronteiriças.
No Acordo $n^{0} 1 / 2009$ do CSS, que contém o plano de trabalho de 2009, uma das metas faz referência a "promover o trabalho e atuação conjunta da vigilância e controle de doenças em região de fronteira”. A perspectiva de atuação nessas situações pela Unasul pode se observar nos objetivos de "propiciar o intercâmbio de experiências entre os sistemas de saúde de seus países membros, incluindo o financiamento" e "desenhar e intercambiar as experiências de prestação de serviços para migrantes da região, de maneira a garantir o acesso à saúde" (Unasul, 2009a). Ratifica-se que a integração entre os países é o objetivo da Unasul, considerando o princípio de solidariedade, e preocupando-se com a efetivação do direito à saúde dos migrantes.

A preocupação com a migração entre os países, assim como a cidadania desse migrante, está registrada em outros documentos, nos quais se lê: "recomendar o estabelecimento de mecanismos para aumentar a participação do cidadão nos serviços de saúde, de modo a capacitar as pessoas sobre seus direitos" e "recomendar o estudo das leis nacionais, o funcionamento dos sistemas de saúde e o acesso dos migrantes, em função da sua vulnerabilidade, para garantir seus direitos de saúde” (Unasul, 2009b).

A concepção do direito à saúde na Unasul como direito de todos e a adoção de sistemas de saúdes universais são registradas nos documentos: "impulsionar politicamente os países da Unasul criando Redes Integradas de Serviços de Saúde baseado na atenção primária para facilitar a criação de sistemas universais de saúde" e "estudar e avaliar a criação de mecanismos de cooperação financiamento e integração entre os países da Unasul" (Unasul, 2009b).

Também se observou referência à necessidade de legitimar as iniciativas de cooperação e integração fronteiriça entre os países membros, de forma a: "estimular a capacidade das autoridades para desenvolver marcos legais para as fronteiras dos países, levando em conta suas particularidades e seu potencial de integração" (Unasul, 2009b).

No documento que apresenta o relatório do I Fórum Sul-Americano de Cooperação Internacional em Saúde da Unasul, realizado em 2011, realizou-se uma mesa-redonda intitulada Saúde e Cooperação nas Fronteiras da Unasul, com objetivo de apresentar 
uma análise da situação da saúde nas fronteiras da Unasul e debater formas e ações de cooperação para essas regiões. Como reflexões finais dessa atividade, ficou expresso no relatório final que:

fronteiras são espaços privilegiados e a população fronteiriça é a primeira a se integrar; por ser flutuante, há muita solidariedade. A Unasul deve pensar o tema de fronteiras como transversal com educação, saúde, drogas, já que aparece em diferentes setores do Estado. Deve pensar ainda em mecanismos de financiamento compensatório para os países. E sobre ações concretas que permitam o acesso aos serviços de saúde de forma recíproca. Finalmente, Unasul deve considerar a adoção de um novo conceito de fronteiras. (Unasul, 2011, p. 61)

A construção social transfronteiriça fica claramente reconhecida no trecho: "as fronteiras são espaços de integração e cooperação onde as pessoas, as comunidades e as instituições interagem e desenvolvem processos sociais, econômicos e culturais espontaneamente" (Unasul, 2012). Esse documento ainda propõe a implementação da Rede Integrada de Serviços de Saúde binacionais ou trinacionais como estratégia para fortalecer a capacidade de resposta dos serviços de saúde dos países da Unasul.

A Rede de Escolas Técnicas de Saúde (Rets) e o grupo técnico de desenvolvimento de sistemas de saúde universais foram criados para impulsionar ações para defender as diretrizes propostas pela Unasul. No informe da primeira reunião ordinária do grupo técnico de desenvolvimento de sistemas de saúde universais, em 2013, há um tratamento especial às fronteiras, propondo a elaboração de uma ferramenta de diagnóstico de saúde nas fronteiras com o prazo de execução de seis meses, sob responsabilidade de Chile e Paraguai, e atualmente sob responsabilidade do Instituto SulAmericano de Governo em Saúde (Isags), organismo intergovernamental vinculado e fruto das discussões de saúde na Unasul (2013).

No plano operativo do Isags de 2013, existem referências aos problemas na esfera da saúde pública enfrentados pelos transfronteiriços, reconhecendo que essa população precisa de maior atenção, uma vez que esses territórios não estão integrados com os grandes centros, de onde surge a necessidade de "fortalecer os serviços de saúde no âmbito das fronteiras" (Unasul, 2012).

No Plano Quinquenal 2010-2015 do CSS, reforçase o desafio de integração, com ênfase nas questões sociais. Assim: "o processo de integração, no entanto, deve ser acompanhado de políticas social de saúde, educação, saneamento básico, emprego e geração de renda para garantir os princípios democráticos e exercício dos direitos humanos" (Unasul, 2010).

$\mathrm{Na}$ declaração $\mathrm{n}^{0}$ 3/2015 do CSS, que trata do plano operativo anual do Isags 2016, ainda é possível encontrar referências às regiões fronteiriças, como a proposta de reunião técnica para verificar como a migração nelas afeta os serviços de saúde, ou seja, mais uma vez, procura-se um diagnóstico que retrate a realidade desse processo de transfronteirização no campo da saúde (Unasul, 2015).

Pode-se afirmar que a Unasul trouxe outra proposta para o desenvolvimento regional dos países sul-americanos, com a inclusão de valores éticos e morais. A criação de grupos técnicos com temas específicos - como a garantia e a melhoria de acesso a medicamentos, a defesa dos sistemas universais de saúde, a capacitação de recurso humano em saúde e o reconhecimento de determinantes sociais em saúde - é uma ação concreta nessa direção.

Segundo Buss e Ferreira (2011), o SGT-11 e a RMS diferem consideravelmente do Conselho de Saúde da Unasul, pois as decisões têm caráter vinculante. Os autores ressaltam a contribuição para uma integração baseada em princípios de solidariedade e complementaridade, que certamente potencializará o desenvolvimento da região e colaborará para a melhoria nas condições de vida e saúde dos sul-americanos.

A integração transfronteiriça abrange um conjunto de ações coordenadas entre iniciativas formais (vértice) e informais (base). Compreendese que a regulamentação por meio de acordos e legislações não é uma resolução definitiva, porém são instrumentos condicionadores do comportamento humano. As relações formal e informal são complementares e essenciais para a harmonia na fronteira (Bento, 2015). 
O diagnóstico dos processos de transfronteirização na saúde foi pauta nas duas instituições estudadas. Entretanto, o que se verifica é que muitas propostas não se concretizaram. A população transfronteiriça aprendeu a conviver com essa dinâmica e muitas vezes se utiliza de artifícios para garantir acesso aos serviços, por exemplo, a adulteração de documentos ou a utilização da dupla nacionalidade (Campos, 2017). Albuquerque (2012, p. 202) definiu que "viver na fronteira é geralmente também viver da fronteira", sendo um pêndulo que oscila ora para um lado, ora para outro. Isso decorre das condições políticas e econômicas oferecidas por cada Estado.

Para Haesbaert (2014), limites são componentes indissociáveis das fronteiras, especialmente quando estas são definidas essencialmente sob sua conotação política. As cidades fronteiriças sofrem direta ou indiretamente os efeitos de crises e crescimentos que ocorrem nos países em que estão inseridas e naqueles que lhe são contíguos. Desse modo, suas funções e seus fluxos são modificados ao longo do tempo (Carneiro, 2016).

O espaço geográfico é complexo, constituído por um sistema de objetos e ações com inúmeras articulações verticais e horizontais: as "horizontalidades" expressariam o território-zona, já as “verticalidades” traduziriam o território-rede. Esses conceitos explicam a duplicidade existente nas áreas de fronteira, onde são vistas pelos respectivos governos centrais como territórios-zona para efeitos de ordenamento territorial; todavia, convertem-se em territórios-rede para as populações locais/regionais, como estratégia de subsistência (Moura Filho, 2010; Santos, 2012).

Santos (2012) esclarece que o território continua a ser utilizado como palco de ações isoladas e no interesse conflitante de atores isolados, agravando desequilíbrios e sem verdadeira produtividade espacial. Em vez de ser instrumento de igualdade individual e de fortalecimento da cidadania, o território mantém a criação de cidadãos desiguais, em que o valor do indivíduo depende do lugar em que ele está.

O Estado Nação surge para promover tanto uma territorialidade de controle de acesso como no sentido de classificação e nomeação conforme local de nascimento. Toda existência legal dos indivíduos dependerá de sua condição territorial nacional. Todos que vivem dentro de seus limites tendem, em determinados momentos, a serem vistos como “iguais". Por isso, toda relação de poder espacialmente mediada é também produtora de identidade, uma vez que controla, distingue, separa e, consequentemente, nomeia e classifica indivíduos e grupos sociais (Haesbaert, 2014). Existe dificuldade em aceitar recortes espaciais não coincidentes com os territórios político-administrativos.

Com a transfronteirização construída pelos transfronteiriços, o limite internacional vai sendo ultrapassado, dando origem à nova territorialidade, a transfronteiriça, com a passagem de um conceito de fronteira-separação para um de fronteira-cooperação (Lemos; Ruckert, 2011). Os fluxos transfronteiriços nesse novo contexto imprimem novas dinâmicas aos territórios na região geopolítica da América do Sul. No Brasil, esse novo conceito foi reconhecido pelo Programa de Desenvolvimento da Faixa de Fronteira (PDFF) (Scherma; Oliveira, 2014).

Os órgãos de integração regional, ao abordarem as questões sociais e culturais, devem promover a aproximação entre os interesses dos Estados, aliando-os aos da sociedade, assim favorecendo a formação de uma identidade transnacional (Andrade; Ribeiro, 2016). A ausência de uma consciência de identidade comum latino-americana a partir de determinados valores constitui-se em empecilho para que mudanças se estabeleçam de forma mais abrangente nos países que compõem a região. Nesse contexto, é necessário descobrir o lugar que cabe à América Latina na sua história e, além disso, buscar a projeção da região como unidade (Miranda; Cademartori, 2016).

\section{Considerações finais}

As preocupações expressadas na maioria dos documentos analisados dizem respeito a temas relacionados à vigilância sanitária, à vigilância epidemiológica e a aspectos administrativos do trânsito em pontos de fronteira. Foram evidenciadas diferenças importantes entre os objetivos e os preceitos que fomentam o Mercosul e a Unasul. É importante destacar que os trabalhos executados 
por essas instituições no campo da saúde pública merecem reconhecimento, pois a vigilância em saúde e a regulação dos serviços e do mercado de trabalho na área são relevantes, tanto na perspectiva econômica quanto na social.

Também cabe ressaltar que, apesar de distintas, as instituições podem ser complementares no desenvolvimento e integração dos países da América do Sul. Contudo, com a criação da Unasul, observa-se que o diálogo e as negociações entre os países atingiram maior cumplicidade e solidariedade. No Mercosul, a institucionalização recente do subgrupo Integração Fronteiriça revela que a população e os processos transfronteiriços estão sendo objeto de análise e maior preocupação dessa instituição.

Apesar de os dois órgãos não possuírem políticas específicas para regiões fronteiriças, os processos de integração regional podem ter início por meio do comércio e da economia, mas devem avançar na questão social. Integrar não significa menosprezar nacionalidades ou anular identidades, muito menos intervir nos assuntos soberanos dos Estados. Pela análise documental, os limites compartilhados entre os países, as fronteiras, há mais de duas décadas são alvo de discussões em diversos grupos técnicos do Mercosul, principalmente ligados ao controle e à vigilância em saúde, suscitando a expectativa da melhoria da integração nos municípios fronteiriços, por meio da legitimação dos processos de transfronteirização, e até mesmo a institucionalização de iniciativas já executadas nesses municípios. Contudo, na prática, pouco se avançou. Não se verificaram propostas de mudanças nos dispositivos legais nem a outorga de autonomia para essas populações.

Por fim, cabe ressaltar as ameaças aos processos de integração, especialmente no âmbito da Unasul, face às recentes mudanças políticas nos países da região, com ascensão de governos liberais/conservadores, cuja orientação ideológica vai em direção contrária aos chamados governos progressistas, que governaram vários países da região neste início de século. Apesar disso, a América do Sul apresenta instituições políticas e administrativas que podem colaborar na superação dos problemas de forma articulada, assegurando a paz, a democracia e a garantia dos direitos humanos. A ideia de uma cidadania latinoamericana plena favorece a universalização de direitos e permite conquistas sociais importantes frente ao opressor e explorador capitalismo econômico. Cabe também aos cidadãos sulamericanos o desafio de reconhecer-se como parte integrante desses organismos e lutarem pela manutenção e ampliação dos direitos sociais nesses países.

\section{Referências}

\section{AGUSTINI, J.; NOGUEIRA V. M. R. A}

descentralização da política nacional de saúde nos sistemas municipais na linha da fronteira Mercosul. Serviço Social \& Sociedade, Curitiba, n. 102, p. 222-243, 2010. Disponível em:

<https://bit.ly/3b7EBoN>. Acesso em: 31 ago. 2017.

ALBUQUERQUE, J. L. C. Limites e paradoxos da cidadania no território fronteiriço: o atendimento dos brasiguaios no sistema público de saúde em Foz do Iguaçu (Brasil). Geopolítica, Madri, v. 3, n. 2, p. 185-205, 2012.

ANDRADE, M. T.; RIBEIRO, A. C. A necessidade de inclusão de uma agenda plural para promover a parceria Estado-sociedade na integração econômica no Mercosul. Revista da Secretaria do Tribunal Permanente de Revisão, Assunção, v. 4, n. 8, p. 136-156, 2016.

BARDIN, L. Análise de conteúdo. 3. ed. Lisboa: Edições 70, 2011.

BENTO, F. R. O papel das cidades-gêmeas de fronteira na integração regional sul-americana. Conjuntura Austral, Porto Alegre, v. 6, n. 27-28, p. 40-53, 2015. Disponível em: <https://bit.ly/ 3b4 $\mathrm{X}_{3} \mathrm{XU}>$. Acesso em: 31 ago. 2017.

BIANCHIN, A.; SCHLOGEL, D. A.; MACIEL, R. Mercosul e a perspectiva econômica da integração latino-americana. Orbis Latina, Foz do Iguaçu, v. 5, n. 2, p. 179-199, 2016. Disponível em: <https://bit.ly/2QrLQZL>. Acesso em: 30 set. 2017. 
BUSS, P. M; FERREIRA, J. R. Cooperação e integração regional em saúde na América do Sul: a contribuição da Unasul-Saúde. Ciência \& Saúde Coletiva, Rio de Janeiro, v. 16, n. 6, p. 2699-2711, 2011. Disponível em: <https://bit.ly/2IXyb8u>. Acesso em: 31 jul. 2017.

CAMPOS, H. A. O papel estratégico de cidades gêmeas no controle de mercadorias em regiões de fronteira no contexto do Mercosul: Uruguaiana (BR) e Paso de los Libres (AR). Redes, Santa Cruz do Sul, v. 22, n. 1, p. 46-73, 2017.

CANDEAS, A. A integração Brasil-Argentina: história de uma ideia na "visão do outro". Brasília, DF: Funag, 2010.

CARNEIRO, P. C. Fronteiras irmãs: transfronteirizações na Bacia do Prata. Porto Alegre: Ideograf, 2016.

CECHINEL, A. et al. Estudo/análise documental: uma revisão teórica e metodológica. Criar Educação, Florianópolis, v. 5, n. 1, 2016.

DESIDERÁ NETO, W. A.; PENHA, B. As regiões de fronteira como laboratório da integração regional no Mercosul. Boletim de Economia e Política Internacional, Brasília, DF, n. 22, p. 33-49, 2016.

GIOVANELLA, L. et al. Saúde nas fronteiras: acesso e demandas de estrangeiros e brasileiros não residentes ao SUS nas cidades de fronteira com países do Mercosul na perspectiva dos secretários municipais de saúde. Cadernos de Saúde Pública, Rio de Janeiro, v. 23, n. 2, p. 251-266, 2007.

GOMES, J. F. F. A Rede Mercocidades na integração sul-americana: a paradiplomacia no Mercosul e na Unasul. Revista InterAção, Santa Maria, v. 8, n. 8, p. 52-69, 2015. Disponível em: <https://bit.ly/2UfuPCY>. Acesso em: 30 set. 2017.

HAESBAERT, R. O mito da desterritorialização: do "fim dos territórios" à multiterritorialidade. Rio de Janeiro: Bertrand Brasil, 2014.
KRYKHTINE, F. B. A criação da Unasul Saúde e do Isags e as estratégias de cooperação em saúde na América do Sul: um estudo exploratório. 2014. Dissertação (Mestrado Profissional em Saúde Global e Diplomacia da Saúde) - Escola Nacional de Saúde Pública Sergio Arouca, Rio de Janeiro, 2014.

LEMOS, B. O.; RUCKERT, A. A. A região transfronteiriça Santana do Livramento-Rivera: cenários contemporâneos de integração/ cooperação. Revista de Geopolítica, Natal, v. 2, n. 2, p. 49-64, 2011.

MERCOSUL - MERCADO COMUM DO SUL. Mercosul/SGT $n^{0} 11$, ata $n^{0}$ 02/oo. XI reunião ordinária do subgrupo de trabalho no 11 "Saúde", Montevidéu, 2oooa. Disponível em: <https://bit.ly/ 2TYOMPA>. Acesso em: 30 nov. 2016.

MERCOSUL - MERCADO COMUM DO SUL. Mercosul/SGT n ${ }^{0}$ 11/ata ${ }^{0}$ 03/oo. XII reunião ordinária do subgrupo de trabalho $n^{\circ} 11$ "Saúde", Montevidéu, 2ooob. Disponível em: <https://bit.ly/ 2TYOMPA>. Acesso em: 30 nov. 2016.

MERCOSUL - MERCADO COMUM DO SUL. Mercosul/GMC Res. n 21/o1. Pauta negociadora do SGT no 11 "Saúde" (Revogação da Resolução $G M C n^{\circ}$ 4/98), Montevidéu, 2001. Disponível em: <https://bit.ly/2TYOMPA>. Acesso em: 30 nov. 2016.

MERCOSUL - MERCADO COMUM DO SUL. Mercosul/SGT $n^{0}$ 11/ata $\mathrm{n}^{0}$ 01/O2. XVII reunião ordinária do subgrupo de trabalho $n^{\circ} 11$ "Saúde", Montevidéu, 2002. Disponível em: <https://bit.ly/ 2TYOMPA>. Acesso em: 30 nov. 2016.

MERCOSUL - MERCADO COMUM DO SUL. Mercosul/SGT $n^{0} 11 /$ ata $n^{0}$ o1/o3. XX reunião ordinária do subgrupo de trabalho $n^{\circ} 11$ "Saúde", Montevidéu, 2003a. Disponível em: <https://bit.ly/ 2TYOMPA>. Acesso em: 30 nov. 2016.

MERCOSUL - MERCADO COMUM DO SUL. Mercosul/SGT $\mathrm{n}^{0}$ 11/ata $\mathrm{n}^{0}$ 02/03. XXI reunião ordinária do subgrupo de trabalho $n^{o} 11$ "Saúde", 
Montevidéu, 2003b. Disponível em: <https://bit.ly/ 2TYOMPA>. Acesso em: 30 nov. 2016.

MERCOSUL - MERCADO COMUM DO SUL. Mercosul/GMC Res. ${ }^{0}$ o6/o5. Pauta negociadora do SGT no 11 "Saúde" (Revogação da Res. GMC no 21/o1), Montevidéu, 2005a. Disponível em: <https://bit.ly/2TYOMPA>. Acesso em: 30 nov. 2016.

MERCOSUL - MERCADO COMUM DO SUL. Mercosul/SGT $n^{0}$ 11/ata $n^{0}$ 01/05. XXIV reunião ordinária do subgrupo de trabalho $n^{\circ} 11$ "Saúde", Montevidéu, 2005b. Disponível em: <https://bit.ly/ 2TYOMPA>. Acesso em: 30 nov. 2016.

MERCOSUL - MERCADO COMUM DO SUL. Mercosul/GMC Res. ${ }^{0}$ 13/o7. Pauta negociadora do SGT no 11 "Saúde" (revogação da Res. GMC no o6/o5), Montevidéu, 2007. Disponível em: <https://bit.ly/2TYOMPA>. Acesso em: 30 nov. 2016.

MERCOSUL - MERCADO COMUM DO SUL. Mercosul/SGT $\mathrm{n}^{0}$ 11/ata $\mathrm{n}^{0}$ 02/o9. XXXIII reunião ordinária do subgrupo de trabalho $n^{\circ} 11$ "Saúde", Montevidéu, 2009. Disponível em: <https://bit.ly/ 2TYOMPA>. Acesso em: 30 nov. 2016.

MERCOSUL - MERCADO COMUM DO SUL. Mercosul/SGT $\mathrm{n}^{0} 11 /$ ata $\mathrm{n}^{0}$ 02/10. XXXV reunião ordinária do subgrupo de trabalho $n^{\circ} 11$ "Saúde", Montevidéu, 2010. Disponível em: <https://bit.ly/ 2TYOMPA>. Acesso em: 30 nov. 2016.

MERCOSUL - MERCADO COMUM DO SUL. Mercosul/SGT n ${ }^{0} 11 /$ ata $\mathrm{n}^{0}$ 02/11. XXXVII reunião ordinária do subgrupo de trabalho no 11 "Saúde", Montevidéu, 2011. Disponível em: <https://bit.ly/ 2TYOMPA>. Acesso em: 30 nov. 2016.

MERCOSUL - MERCADO COMUM DO SUL. Mercosul/SGT $n^{0} 11 /$ ata $n^{0}$ 01/14. XLII reunião ordinária do subgrupo de trabalho no 11 "Saúde", Montevidéu, 2014. Disponível em: <https://bit.ly/ 2TYOMPA>. Acesso em: 30 nov. 2016.

MERCOSUL - MERCADO COMUM DO SUL. Mercosul/SGT $\mathrm{n}^{0} 11 /$ ata $\mathrm{n}^{0} \mathrm{02} / 15$. XLIV reunião ordinária do subgrupo de trabalho no 11 "Saúde", Montevidéu, 2015b. Disponível em: <https://bit.ly/ 2TYOMPA>. Acesso em: 30 nov. 2016.

MERCOSUL - MERCADO COMUM DO SUL. Institucional Mercosur, Montevidéu, 4 fev. 2016a. Disponível em: <https://bit.ly/2IXLqpI >. Acesso em: 31 ago. 2016.

MERCOSUL - MERCADO COMUM DO SUL. Mercosul/SGT n ${ }^{0}$ 18/ata $n^{0}$ 01/16. I reunión ordinaria del subgrupo de trabajo $n^{\circ} 18$ "Integración Fronteriza", Montevidéu, 2016b. Disponível em: <https://bit.ly/2TYOMPA>. Acesso em: 30 nov. 2016.

MIRANDA, J. A. A.; CADEMARTORI, S. U. Processos constituintes e novas condições do estado na América Latina: uma identidade comum? Nomos, Fortaleza, v. 36, n. 1, p. 223-239, 2016. Disponível em: <https://bit.ly/2WriGhc>. Acesso em: 31 ago. 2017.

MOURA FILHO, J. L. Multiterritorialidade em regiões transfronteiriças: estudo de duas cidades gêmeas na fronteira Brasil-Uruguai. 2010. Tese (Doutorado em Desenvolvimento Regional) - Universidade de Santa Cruz do Sul, Santa Cruz do Sul, 2010.

NEVES, A. J et al. (Org.). Segurança pública nas fronteiras, diagnóstico socioeconômico e demográfico: Estratégia Nacional de Segurança Pública nas Fronteiras (Enafron). Brasília, DF: Secretaria Nacional de Segurança Pública, 2016.

ONU - ORGANIZAÇÃO DAS NAÇÕES UNIDAS. Declaração universal dos direitos humanos. Genebra, 1948. Disponível em: <https://bit.ly/ 2WpoDLu>. Acesso em: 28 fev. 2018.

SANTOS, M. Espaço do cidadão. 7. ed. São Paulo: Edusp, 2012.

SCHERMA, M. A.; OLIVEIRA, J. P. Integração na fronteira Brasil-Uruguai na área da saúde: um panorama. In: CONGRESO URUGUAYO DE 
CIENCIA POLÍTICA: ¿QUÉ CIENCIA POLÍTICA PARA QUÉ DEMOCRACIA?, 5., 2014, Montevidéu. Anais... Montevidéu: Aucip, 2014.

TAJRA, J. L. F.; MARTINS, M. D. O parlamento do Mercosul e a cidadania sul-americana. Revista Eletrônica de Ciência Política, Curitiba, v. 5, n. 2, p. 132-144, 2014. Disponível em: <https://bit.ly/ 39XJ31Y>. Acesso em: 30 set. 2017.

TRINDADE, A. A. M. Cooperação internacional em saúde no Mercosul: Argentina, Brasil e Uruguai. 2016. Tese (Doutorado em Ciências Sociais) Universidade Federal da Bahia, Salvador, 2016.

UNASUL - UNIÃO DAS NAÇÕES SUL-

AMERICANAS. Acordo entre os ministros e ministras de saúde dos Estados Membros da Unasul: estabelecimento do Conselho de Saúde Sul-Americano. Quito, 2008. Disponível em: <https://bit.ly/2QtwUtT>. Acesso em: 30 nov. 2016.

UNASUL - UNIÃO DAS NAÇÕES SULAMERICANAS. Acordo $n^{\circ} 1 / 2009$ do Conselho de Saúde Sul-Americano: estruturação CSS. Quito, 20o9a. Disponível em: 〈https://bit.ly/2QtwUtT>. Acesso em: 30 nov. 2016.

UNASUL - UNIÃO DAS NAÇÕES SUL-

AMERICANAS. Resolução no 8/2009 da reunião do Conselho de Saúde Sul-Americano: constituição do grupo técnico de sistemas de saúde universais (SUS). Quito, 20ogb. Disponível em: <https://bit. ly/2QtwUtT>. Acesso em: 30 nov. 2016.
UNASUL - UNIÃO DAS NAÇÕES SUL-AMERICANAS. Plano quinquenal 2010-2015: Conselho de Saúde SulAmericano. Quito, 2010. Disponível em: <https://bit.ly/2QtwUtT>. Acesso em: 30 nov. 2016.

UNASUL - UNIÃO DAS NAÇÕES SULAMERICANAS. Relatório do $1^{\circ}$ fórum sulamericano de cooperação internacional em saúde. Quito, 2011. Disponível em: <https://bit.ly/ 2QtwUtT>. Acesso em: 30 nov. 2016.

UNASUL - UNIÃO DAS NAÇÕES SULAMERICANAS. Ata do comitê coordenador preparatório da VII Reunião Conselho de Saúde Sul-Americano. Quito, 2012. Disponível em: <https://bit.ly/2QtwUtT>. Acesso em: 3o nov. 2016.

UNASUL - UNIÃO DAS NAÇÕES SULAMERICANAS. Informe da 1 a reunião ordinária do grupo técnico de desenvolvimento de sistemas de saúde universais. Quito, 2013. Disponível em: <https://bit.ly/2QtwUtT>. Acesso em: 30 nov. 2016.

UNASUL - UNIÃO DAS NAÇÕES SULAMERICANAS. Declaração $n^{\circ}$ 3/2015 do Conselho de Saúde Sul-Americano: plano operativo anual, Isags 2016. Quito, 2015. Disponível em: <https://bit.ly/2QtwUtT>. Acesso em: 30 nov. 2016.

UNASUL - UNIÃO DE NAÇÕES SULAMERICANAS. Foro para o progresso e integração da América do Sul (Prosul). Brasília, DF, 5 jun. 2016. Disponível em: <https://bit.ly/3dgbUCt $>$. Acesso em: 30 jul. 2016. 